\title{
COMPLIANCE NA REALIZAÇÃO DA FUNÇÃO SOCIAL DA EMPRESA
}

\section{COMPLETION IN THE REALIZATION OF THE COMPANY'S SOCIAL FUNCTION}

\section{MARCELO NEGRI SOARES}

Advogado e contabilista. Professor Visitante da Coventry University (UK), no Programa de Doutorado em Direito, Administração e Negócios. Professor e Pesquisador do Programa de Mestrado e Doutorado em Direito UniCesumar - Centro Universitário Cesumar, na linha Efetividade da Justiça e Direitos da Personalidade, lecionando a disciplina Acesso à justiça e Meios adequados de solução de conflitos. Pós-Doutorado pela Uninove/SP (2017). Doutor pela Pontifícia Universidade Católica de São Paulo (2013). Mestre pela PUC-SP (2005). Graduado pela Universidade Estadual de Maringá/PR (1997). Especialista em Direito Processual pela Universidade Paulista (1998), em Direito Comercial pelo Mackenzie (2006), em Direito Público pela Escola Federal de Direito (2008). Formado em Contabilidade pelo IEEM - Maringá (1989). Funcionário do Banco do Brasil S.A. por mais de 20 (vinte) anos (última função: advogado pleno). Assessor da PGFN (1997/1998). Foi professor de Direito da UNINOVE, UNIP, PUC-RIO e da Faculdade Nacional de Direito (UFRJ). Atua em todo o território brasileiro e em Brasília (DF). Membro do IBDC e IBCJ. Experiência como diretor jurídico-empresarial. Atuação - DIREITOS: PROCESSUAL, EMPRESARIAL, CONTRATUAL, BANCÁRIO, TRABALHO, TRIBUTÁRIO E CIVIL. E-mail: negri@negrisoares.com.br.

\section{MARIA GISELA CAMPOS}

Graduada em Letras pela Universidade Estadual de Maringá (1987). 


\section{Personalidade Acadêmica Homenageada:}

\section{Florisbal de Souza Del'Olmo (Professor Convidado - UNICURITIBA)}

\section{REMUMO}

Este artigo tem por escopo apresentar o compliance como parte essencial da realização da função social da empresa, com consequências positivas sócio ambientais e reflexos na minimização de responsabilidades no âmbito do direito empresarial. Nesse objetivo, fazemos incursões históricas, principiológicas e conceituais, em torno da responsabilidade empresarial, para introduzir os aspectos dogmáticos e legais, empós, desenvolver o tema de fundo, ligando o compliance ao ambiente empresarial e os tipos de responsabilização, passando pela proteção contra a corrupção instituída, com vistas à redução de desigualdades sociais.

PALAVRAS-CHAVE: Direito empresarial; Compliance; Responsabilidade.

\section{ABSTRACT}

This article aims to present compliance as an essential part of achieving the company's social function, with positive socio-environmental consequences and reflexes in minimizing responsibilities in the scope of business law. In this objective, we make historical, conceptual and conceptual incursions around corporate responsibility, to introduce dogmatic and legal aspects, empos, to develop the fundamental theme, linking compliance to the business environment and the types of accountability, and protection against corruption, with a view to reducing social inequalities.

KEYWORDS: Business law; Compliance; Responsability

\section{INTRODUÇÃO}

O presente artigo traz uma análise do compliance empresarial, no sentido de coadunar um melhor entrosamento das pessoas envolvidas no desempenho da atividade empresarial, propiciando aumento nos ativos, mitigando custos 


\section{Personalidade Acadêmica Homenageada:}

Florisbal de Souza Del'Olmo (Professor Convidado - UNICURITIBA)

desnecessários de forma aliada com a Responsabilidade Social Empresarial, em conformidade com as legislações pertinentes, respeitando o meio ambiente, ecológico, do trabalho de acordo com normas constitucionais.

A responsabilidade social empresarial é de suma importância, pois abarca todos os ramos de atividade, não apenas as grandes corporações, mas também as empresas de pequeno e médio porte, assim como as empresas estatais e suas subsidiárias, pois quando se atua de forma correta, com critérios idôneos, toda a coletividade se beneficia.

O avanço tecnológico propiciou às empresas melhor condições de gerenciar os negócios, favorecendo os controles internos, os investimentos, as ações sociais, etc. Por outro lado, também o governo atua de forma mais incisiva na fiscalização e cobrança de tributos, o que pode ter um efeito colateral, fazendo com que algumas empresas na ânsia de burlar o fisco, acaba cometendo atos ilícitos, corrompendo funcionários públicos, favorecendo a corrupção e a lavagem de dinheiro, ocasionando sérios problemas para a sociedade, para o Estado e para a própria empresa.

Como se sabe, a empresa é primeiramente fonte geradora de recursos, porém, conforme os constitucionais e critérios legais, morais e éticos, a empresa possui um papel social, que não pode ser deixado de lado. As demandas sociais do século XXI vão além da propriedade privada, e a própria sociedade possui critérios críticos para que a empresa possa subsistir.

\section{DESENVOLVIMENTO: A FUNÇÃO SOCIAL DA EMPRESA}

A empresa, no modelo que conhecemos hoje, passou por inúmeras mudanças em atendimento as demandas sociais, a competitividade, a influência do mercado externo, e cenário político com as oscilações dos mercados financeiros, tornando cada vez mais difícil empreender em conformidade com a legislação fiscal, tributária e demais normativas e princípios gerais com relação à responsabilidade social que deve pautar o dia-a-dia das empresas. 


\section{Personalidade Acadêmica Homenageada:}

\section{Florisbal de Souza Del'Olmo (Professor Convidado - UNICURITIBA)}

$\mathrm{Na}$ idade contemporânea não é mais possível empreender apenas vislumbrando o lucro, por isso a necessidade de criar mecanismos para alavancar os negócios e concomitante respeitar o meio ambiente, atinar sobre a responsabilidade social com relação aos colaboradores e toda a sociedade que de alguma forma se beneficia com a empresa.

O modelo de exploração capitalista que conhecemos hoje se utiliza de práticas potencialmente nociva ao meio ambiente. Trata-se de um modelo econômico, político e social que entende o meio ambiente como um depósito de riquezas, disponível à exploração de forma constante. Desta forma cabe à população, ao poder público criar condições de prevenir, fiscalizar e punir os infratores, visto que não é possível que as empresas atuem de forma indiscriminada e até criminosa em detrimento do bem maior que é a vida do planeta.

Veja que o direito de propriedade não é um direito absoluto, pois que a propriedade deve cumprir sua função social, seja na área urbana ou rural. Conforme preleciona o Art. 5, XXIII, da Constituição Federal " a propriedade atenderá a sua função social", e mais, o art. 170, caput e inciso III, coloca que "A ordem econômica, fundada na valorização do trabalho humano, e na livre iniciativa, tem por fim assegurar a todos existência digna, conforme os ditames da justiça social, observados os seguintes princípios: função social da propriedade"

De acordo com o texto constitucional, toda pessoa tem o direito de empreender, pois é livre a iniciativa, porém deve-se observar princípios básicos relacionados a função social da atividade que se propõe a exerce.

\section{DESENVOLVIMENTO HISTÓRICO DO DIREITO COMERCIAL}

O Direito Comercial teve provavelmente na Idade Média o seu primeiro conjunto de regras jurídicas próprias. Trata o Direito Comercial em um momento histórico, cuja origem está ligada à afirmação de uma civilização burguesa e urbana, desenvolvendo-se um novo espírito empreendedor e uma nova organização nos negócios. 


\section{Personalidade Acadêmica Homenageada:}

Florisbal de Souza Del'Olmo (Professor Convidado - UNICURITIBA)

De forma sucinta, a evolução do Direito Comercial, pode ser dividida em três fases:

$1^{\circ-}$ - dos usos e costumes (fase objetiva, que se inicia na Antiguidade, consolidando -se fundamentalmente na Idade Média, indo até 1807, ano da edição do Código Comercial Francês;

$2^{\circ}$ - da teoria dos atos de comércio (fase objetiva, de 1807 até 1942, ano marcado pela edição do Código Civil italiano);

3ํ- da teoria da empresa (fase subjetiva moderna, a partir de 1942 até o presente momento)

Destarte, fazendo um paralelo do direito comercial conforme foi construído no decorrer dos séculos com o Direito Empresarial com o está positivado hoje, podemos perceber que o direito de modo geral sempre regulou a vida em sociedade, assim, o Direito Empresarial regula as atividades comerciais que são praticamente a estrutura econômica do país, pois faz circular o dinheiro e cria postos de trabalho.

No Brasil, foi elaborado um projeto de Código do Comércio que tramitou no poder legislativo de 1834 até 1850, ano em que foi sancionada a Lei n.556, de 25 de junho de 1.850 - conhecida como Código Comercial brasileiro.

Com inspiração nos Códigos Comerciais da França, da Espanha e de Portugal. No mesmo ano da sua edição foi regulamentado pelo Decreto n. 737 , de 1.850 .

O Código Comercial brasileiro de 1850 adotava a teoria dos atos do comércio. Na segunda metade do século $X X$, a jurisprudência e a doutrina brasileiras começaram a perceber a insuficiência dessa teoria e passaram a admitir a teoria da empresa. Isso pode ser percebido na concepção de várias normas, como a Lei n. 8.078/90 - Código de defesa do Consumidor.

Com a vigência do Código Civil de 2002, revogou-se a primeira parte do Código Comercial de 1.850 (a maior e principal parte). A partir disso, o Direito Empresarial deixou de ter como fonte principal o Código Comercial, passando a ser regulado pelo Código Civil.

O Código Civil de 2002 adotou a teoria de empresa em detrimento da teoria dos atos do comércio, seguindo em grande medida disposições do Código Civil 


\section{Personalidade Acadêmica Homenageada:}

Florisbal de Souza Del'Olmo (Professor Convidado - UNICURITIBA)

italiano de 1942, especialmente nas disposições sobre o direito obrigacional e o direito de empresa.

O Direito Empresarial passou a ter como disciplina qualquer atividade profissional econômica e organizada para a produção ou a circulação de bens ou de serviços, exceto as atividades intelectuais.

Art. 966, CC/2002 Considera-se empresário quem exerce profissionalmente atividade econômica organizada para a produção ou a circulação de bens ou serviços. Parágrafo único: Não se considera empresário quem exerce profissão intelectual, de natureza científica, literária ou artística, ainda com o concurso de auxiliares ou colaboradores, salvo se o exercício da profissão constituir elemento de empresa.

\section{RESPONSABILIDADE SOCIAL EMPRESARIAL, SEUS MARCOS REGULATÓRIOS}

A Responsabilidade Social da Empresa abarca várias instâncias, quais sejam, a preservação do meio ambiente, a preservação do meio ambiente do trabalho, as condições sociais no entorno das empresas, ou seja, as condutas socioambientais dos empresários vão além dos domínios da sua propriedade, pois os critérios de produtividade devem vincular com a ideia de responsabilização por todas as consequências decorrentes de atitudes tomadas.

Uma organização socialmente responsável deve se comportar de maneira a proteger e melhorar a qualidade de vida da sociedade.

O princípio da responsabilização exige a imputação de sanções penais, administrativas e civis ao causador do dano ambiental, inclusive ao próprio Estado.

Meio ambiente e direito de propriedade são noções a serem compatibilizadas. O direito de propriedade, outrora ilimitado e absoluto, pela nova ordem constitucional deve cumprir uma função social, e essa, só será concretizada quando houver o respeito à proteção ambiental. A fruição da propriedade não pode legitimar a emissão de poluentes que vão invadir a propriedade de outros indivíduos. O conteúdo da propriedade não reside num só elemento. Há o elemento individual, 


\section{Personalidade Acadêmica Homenageada: \\ Florisbal de Souza Del'OImo (Professor Convidado - UNICURITIBA)}

que possibilita o gozo e o lucro para o proprietário. Mas outros elementos aglutinamse a esse: além do fator social, há o componente ambiental. Não por outra razão, entende o Supremo Tribunal Federal que o direito de propriedade não mais possui caráter absoluto, eis que, sobre o mesmo, pesa grave hipoteca social, a implicar que, descumprida a função social que lhe é inerente (CF, art. 5ำ XXIII), se torne legítima uma intervenção estatal na esfera dominial privada (com respeito aos limites constitucionais). (STF, ADI 2.213-MC, Rel. Min. Celso de Mello, DJ 23.04.2004).

Preleciona o art. 170, CF - A ordem econômica, fundada da valorização do trabalho humano e na livre iniciativa, tem por fim assegurar a todos existência digna, conforme os ditames da justiça social, observado, entre outros, o princípio da defesa do meio ambiente.

Destarte, para o cumprimento da responsabilidade social da empresa, a defesa ao meio ambiente deve estar na pauta dos procedimentos estabelecidos para o desenvolvimento das atividades.

No final dos anos 1960, uma variedade de crises ambientais torna-se evidente e expõe a sua face perversa do ponto de vista social. Diversos eventos promovidos pela Organização das Nações Unidas (ONU) e suas agências, como a Unesco, expuseram esses problemas e incentivaram a busca de soluções. A Conferência das Nações Unidas sobre o Meio Ambiente Humano, realizada em Estocolmo em 1972, é uma referência importante do movimento pelo desenvolvimento sustentável, embora essa expressão ainda não fosse usada. Uma de suas principais contribuições foi vincular a questão ambiental à social e, desse modo, também é um marco na aproximação com o movimento da responsabilidade social. A resolução da Assembleia da ONU de 1986 declarando o desenvolvimento como direito humano, a divulgação do Relatório Brundtland em 1987 e a Conferência das Nações Unidas sobre Meio Ambiente e Desenvolvimento, em 1992 no Rio de Janeiro, são alguns dos inúmeros eventos do movimento do desenvolvimento sustentável. A definição de desenvolvimento sustentável nesse relatório é a seguinte: 


\title{
Personalidade Acadêmica Homenageada: \\ Florisbal de Souza Del'OImo (Professor Convidado - UNICURITIBA)
}

Desenvolvimento sustentável é aquele que atende às necessidades do presente sem comprometer a possibilidade das gerações futuras de atenderem as suas próprias necessidades. (Comissão Mundial sobre Meio Ambiente e Desenvolvimento, p.46)

O capitalismo impulsionou o consumo de tal forma que se não houver um controle por parte do Estado e de organizações que se ocupam das relações com o meio ambiente, a humanidade corre o risco de sofre com escassez dos recursos naturais e para tanto as legislações cuidam de prevenir, reprimir e punir os infratores na esteira das normas administrativas, civis e penais.

\begin{abstract}
A evolução da gestão ambiental empresarial também seguiu caminho similar à da qualidade. A pressão exercida pelas legislações ambientais fez com que as empresas passassem a controlar a poluição gerada nos processos produtivos para não lançar ao meio ambiente. [...] A gestão ambiental alinhada com as estratégias empresariais tem sido estimulada pelo crescimento da preocupação ambiental por amplos setores da sociedade, que têm pressionado as autoridades para tornar as leis mais rigorosas e sua fiscalização mais efetiva. (Barbieri - Cajazeira, 2018, p.57).
\end{abstract}

Conjugando todos os dispositivos, tem-se que o meio ambiente, como patrimônio público e bem de uso comum do povo, deve ser entendido conforme preleciona a lei n. $6.938 / 81$ no art. $3^{\circ}$

o conjunto de condições, leis, influências e interações de ordem física, química e biológica, que permite, obriga e rege a vida em todas as suas formas

A Constituição Federal protege o meio ambiente natural, (Art. 225 incisos I e VII do $\S 1^{\circ}$ ), o meio ambiente artificial, o que trata daquilo que foi construído pelo homem, (arts. 21, XX; 23, XI e X; 182; 183; 5, XXIII), meio ambiente cultural, conceituado como patrimônio cultural brasileiro (arts. 215 e 216).

Estabelecer limites para as ações que afetam o meio ambiente e a comunidade é um dever ético das companhias. Alguns céticos poderiam dizer tratarse mais de uma questão mercadológica ou de uma iniciativa de marketing. Entretanto, muito mais que isso, é dever da empresa se preocupar com a disposição de resíduos e lixo industrial. Além disso, comportamentos displicentes podem custar caro e afetar gravemente os resultados. 


\section{Personalidade Acadêmica Homenageada:}

Florisbal de Souza Del'Olmo (Professor Convidado - UNICURITIBA)

As decisões éticas empresariais afetam diretamente o meio ambiente, suscitam perguntas e estimulam debates, tais como: As necessidades comerciais e humanas justificam o impacto ambiental?

No meio ambiental, assuntos menos utópicos, mas importantes, estão gradativamente sendo colocados em pauta e normatizados por órgãos ambientais em todo o mundo. Haverá um tempo em que a ética como ação espontânea terá desaparecido, pois as medidas e os cuidados ambientais e sociais, além dos procedimentos de sustentabilidade, serão normatizados.

No meio ambiente do trabalho, a previsão normativa encontra-se no art. 200, VIII, da Constituição Federal.

Ao sistema único de saúde compete, além de outras atribuições, nos termos da lei:

VIII-colaborar na proteção do meio ambiente, nele compreendido do trabalho.

Há também convenções internacionais onde o Brasil é signatário, que cuida do tema, como a Convenção 155 da Organização Internacional do Trabalho (OIT), de 1981, adotada na 67ª Conferência Internacional do Trabalho, referindo-se ao "desenvolvimento pelos países, de uma Política de Saúde, Segurança e Meio Ambiente do trabalho, incluindo no local de trabalho, ferramentas, máquinas, agentes químicos e físicos, operações e processos, as relações entre trabalhador e o meio físico", cuidando ainda, no que concerne à fiscalização das condições laborais por um sistema apropriado, aferição dos graus de risco das atividades.

O Código Civil de 1916 era estritamente patrimonialista e individualista, já o Código Civil de 2002 buscou proteger a pessoa humana, estabelecendo três paradigmas: a sociedade, a eticidade e a operabilidade, aproximando-se da Constituição Federal de 1988, que tem um viés humanitário, abarcando, portanto, proteção da dignidade da pessoa humana, valores sociais do trabalho e da livre iniciativa, dentre outros, o que em conjunto com as demais Leis de proteção ao trabalho, ao meio ambiente, propicia um conjunto de ações que desagua na Responsabilidade Social da Empresa. 


\section{Personalidade Acadêmica Homenageada:}

Florisbal de Souza Del'Olmo (Professor Convidado - UNICURITIBA)

Diversas legislações infraconstitucionais, como a Lei n.6.938/81 Política Nacional do Meio Ambiente, o Órgãos como SISNAMA- Sistema Nacional do Meio Ambiente e CONAMA - Conselho Nacional do Meio Ambiente, IBAMA, Instituto Brasileiro do Meio Ambiente e Instituto Chico Mendes de Conservação da Biodiversidade. Esses órgãos são responsáveis por estabelecer padrão de qualidade, zoneamento ambiental, avaliação de impactos ambientais, licenciamento, controle de atividades potencialmente poluidoras, inspeção, fiscalização e vistorias.

Como se pode observar a Responsabilidade Social da Empresa é pautada em diversas legislações, que permeiam uma nova mentalidade no trato com o desenvolvimento dos negócios, com atitudes voltadas para o sócio ambiental, além das práticas comerciais voltadas para a obtenção de lucro.

Princípios, regulamentos e códigos relativos aos negócios, quando elaboradas com elevado consenso internacional, fornecem elementos para as empresas estabelecerem políticas de responsabilidade social de modo mais detalhado, pois se apresentam na forma de recomendações para questões específicas, como relação de trabalho, combate à poluição, transações comerciais.

\section{A RESPONSABILIDADE SOCIAL E EMPRESARIAL X ÉTICA E MORAL}

O direito e a moral tratam de normas de conduta humana que regulam a vida social e muita matéria é regulada de modo exclusivo em cada um desses domínios.

Moral e direito diferem porque as normas legais são produzidas no âmbito do Estado e promulgadas pelo poder público, enquanto as morais são produzidas informalmente no âmbito da sociedade por meio de relações efetivas entre os seus membros.

A obrigatoriedade da norma de direito decorre da capacidade de coação exercida pelos aparelhos estatais. As leis são obrigatórias gostando ou não. Ao passo que a obrigatoriedade da norma moral decorre da convicção de pessoas e grupos de que trata da coisa certa a fazer. Como disse um grande filósofo: "a lei 


\section{Personalidade Acadêmica Homenageada:}

Florisbal de Souza Del'Olmo (Professor Convidado - UNICURITIBA)

constitui o esqueleto da ordem social revestido pela carne e pelo sangue da moralidade. " (Henry Sidgwick, The Methods of ethics, p.459)

As principais semelhanças entre a moral e o direito são as seguintes: as normas legais ou jurídicas e as normas morais são eficazes, pois sem isso não teriam como regular as relações sociais.

A ética normativa trata de questões gerais, a ética empresarial é especificamente voltada para dar respostas aos problemas de natureza moral no âmbito das empresas, relacionada com as políticas, instituições e comportamentos das empresas.

São assuntos corriqueiros os que surgem a respeito dos sistemas econômicos, políticos, jurídicos e outros nos quais os negócios atuam. São questionamentos sobre a moralidade do capitalismo, das leis que afetam as empresas, da estrutura industrial e das práticas sociais dentro das quais os negócios operam. Por exemplo: teria como o capitalismo dar respostas concretas e eficazes aos problemas ambientais? Ou questionar as leis que regulam as concessões de serviços públicos às empresas e as que concedem benefícios fiscais para atrair empreendimento?

Questões que valem para todas as empresas de um modo geral que envolvem questões morais, como por exemplo, critérios relacionados com distribuição dos resultados entre os empregados, doação para políticos em campanhas eleitorais, suborno e corrupção de agentes do governo e mudança de comportamento dos consumidores induzidas por campanhas publicitárias, são questões que tratam primordialmente com seres humanos que sentem, raciocinam, deliberam a atuam com base em seus sentimentos e razões.

A atuação da empresa será boa ou não conforme as decisões que as pessoas tomarem em seu nome, porém a empresa possui obrigação moral e é responsável moralmente por seus atos, pois alguém em seu nome tem obrigação moral com relação a esses atos. 


\section{Personalidade Acadêmica Homenageada:}

Florisbal de Souza Del'Olmo (Professor Convidado - UNICURITIBA)

Os princípios que devem delinear as condutas dos empreendedores são de suma importância para a Responsabilidade Social Empresarial, pois são os princípios que irão dar base para as normativas internas das empresas, na condução dos negócios e no trato com colaboradores, e demais pessoas envolvidas na atividade empresarial. Os princípios, como transparência, comportamento ético, respeito pelos interesses das partes interessadas, respeito pelo estado de direito, respeito as normas internas da companhia, respeito aos direitos humanos, estão delineados na Norma Internacional ISO 26000, como segue,

Norma Internacional ISO 26000, Diretrizes sobre Responsabilidade Social publicada em 1ำ de novembro de 2010 em Genebra-Suiça. No Brasil, no dia 08 de dezembro de 2010, a versão em português da norma, a ABNT NBR ISO 26000, foi lançada em evento da Fiesp, em São Paulo.

Segundo a ISO 26000, a responsabilidade social se expressa pelo desejo e pelo propósito das organizações em incorporarem considerações socioambientais em seus processos decisórios e a responsabilizar-se pelos impactos de suas decisões e atividades na sociedade e no meio ambiente. Isso implica um comportamento ético e transparente que contribua para o desenvolvimento sustentável, que esteja em conformidade com as leis aplicáveis e seja consistente com as normas internacionais de comportamento. Também implica que a responsabilidade social esteja integrada em toda a organização, seja praticada em suas relações e leve em conta os interesses das partes interessadas.

A norma fornece orientações para todos os tipos de organização, independente de ser porte ou localização.

Conforme as diretrizes da norma ISO 26000 é possível verificar os princípios que norteiam tal normativa, quais seja:

Accountability - o termo em inglês significa a obrigação das organizações em ser transparente na prestação de contas sobre sua atuação, informações que sejam relevantes para as pessoas que são atingidas por suas atividades;

Transparência - princípio muito semelhante ao primeiro, neste, convém que a organização divulgue de forma clara, precisa e completa, e em grau razoável e 


\section{Personalidade Acadêmica Homenageada:}

Florisbal de Souza Del'Olmo (Professor Convidado - UNICURITIBA)

suficiente, as políticas, decisões e atividades pelas quais é responsável, inclusive seus impactos conhecidos e prováveis na sociedade e n o meio ambiente. Não se trta de divulgar informações confidenciais consideradas estratégias da empresa. A transparência deve se dar em relação ao propósito, natureza e localização das atividades, a forma como as decisões são tomadas e implementadas, inclusive montantes e aplicações de seus recursos financeiros.

Comportamento ético - Se a empresa tem por objetivo se perpetuar no mercado, deve se pautar pela ética. Uma ação antiética tem o condão de condenar a reputação da organização nos mais diversos segmentos sociais e econômicos. $O$ comportamento ético deve ser incentivado e promovido internamente na organização tendo como alvo seus colaboradores.

Quando se aplica a ética na empresa, é mais fácil governar pois facilita a denúncia de algum comportamento antiético sem medo de represálias.

Respeito pelos interesses das partes interessadas - Uma organização deve responder a todos os interesses das partes a ela relacionadas e envolvidas. Existe uma gama de pessoas ligadas à organização com interesses igualmente válidos, além do proprietário, diretores conselheiros, etc.

A organização deve elencar e identificar todas as partes interessadas e assim reconhecer que tais partes possuem interesses e que muitos deles são legítimos e devem ser levados em consideração, reconhecendo também que algumas partes podem influenciar significativamente a atividade da empresa, seja interna ou externa.

Respeito ao estado de direito - toda organização deve respeitar a ordem social e a legislação, em sentido amplo, que regem a sociedade. O Estado de direito impõe respeito às normas que regem toda a comunidade não sendo permitido o exercício arbitrário do poder. Sociedade e Estado devem observar estritamente o cumprimento do ordenamento jurídico nacional. A organização deve conhecer toda legislação pertinente ao seu negócio e informar a todos dentro da organização sobre sua obrigação de cumprir e implementar essas medidas. 


\section{Personalidade Acadêmica Homenageada:}

Florisbal de Souza Del'Olmo (Professor Convidado - UNICURITIBA)

Respeito pelas normas internacionais de comportamento - ao mesmo tempo que adere ao princípio do estado de direito deve conhecer e aplicar as normas internacionais aplicáveis à sua atividade.

Respeito pelos direitos humanos - Os direitos humanos são direitos inerentes a todas as pessoas viventes no planeta, tendo como fundamento sua dignidade, liberdade de opinião, a educação, o trabalho, dentre outros. Convém que a organização respeite e sempre que possível promova os direitos humanos elencados nos Tratados Internacionais, assim como na Constituição Federal

A norma ISO 26000 apresenta importantíssimas práticas a serem observadas por empresas que desejam elaborar, implementar e executar políticas de sustentabilidade. Assim, toda a organização tem a seu dispor uma excelente ferramenta que poderá ser adotada em toda sua extensão.

\section{PROGRAMA DE COMPLIANCE - RESPONSABILIDADE SOCIAL EMPRESARIAL}

Todo modelo de organização precisa responder com eficiência ao gerenciamento.

A palavra compliance vem do inglês "to comply", que significa seguir regras, instruções, normas, diretrizes ou simplesmente responder a um comando. $O$ compliance pressupõe adesão e respeito a normas e regulamentos.

A implementação do compliance pelas empresas é fundamental no combate à corrupção, cuja atividade assume cinco aspectos fundamentais, segundo o Global Integrity Summit, da Griffith University (Deloitte, 2014)

Regulamentação: regras claras, factíveis e disseminadas, acordadas por todos na sociedade;

Educação: formação e capacitação sobre conceitos de integridade e ética para engajar os envolvidos;

Cooperação: integração e colaboração entre diferentes países e instâncias regulamentares e de investigação; 


\section{Personalidade Acadêmica Homenageada:}

\section{Florisbal de Souza Del'OImo (Professor Convidado - UNICURITIBA)}

Transparência: ferramentas de divulgação, monitoramento e acompanhamento de informações públicas;

Independência: liberdade para investigação e julgamento de casos de corrupção.

Portanto, o compliance é formado por leis, decretos, resoluções, normas, atos e portarias, ou seja, todo o arcabouço regulatório aplicado pelas agências que controlam e regulam o setor no qual a empresa está inserida.

As maiores e mais organizadas corporações também criam suas próprias normativas internas para direcionar o comportamento de seus diretores e executivos e, assim, coibir comportamentos negativos, o compliance pressupõe atender, além da normativa regulatória e legal, as resoluções internas da companhia.

A empresa ética não explora seus colaboradores, não paga propina para os compradores de seus produtos, respeita seus fornecedores e não comete crimes ambientais. Nessa toada é preciso ter normas claras de condutas internas na empresa, para que todas as pessoas envolvidas na atividade estejam afinadas aos regramentos que levam a uma prática condizente com as normas morais e éticas.

A ética é assumida de forma espontânea pelos dirigentes das empresas, já o compliance é uma adesão, é cumprir regras e regulamentos; é trabalhar dentro da lei. O principal objetivo de trabalhar de forma organizada dentro das normativas estabelecidas pelo compliance é evitar corrupção.

O combate a corrupção é um tema essencial em qualquer gestão da Responsabilidade Social Empresarial. A palavra corrupção indica uma variedade de atos moralmente condenáveis associados ao uso indevido do poder, seja de quem o detém ou de quem tem capacidade de influenciá-lo. O termo é mais comumente associado à esfera pública, mais especificamente à relação entre agentes das esferas públicas e privadas.

Os problemas que a corrupção produz são tantos e tão conhecidos que dispensa demonstração. As práticas de corrupção prejudicam o desenvolvimento do país e lançam dúvidas sobre a legalidade das instituições democráticas, pois a política de coalizão institucionalizada no Brasil, favorece a corrupção nos mais variados setores da economia. 


\section{Personalidade Acadêmica Homenageada: \\ Florisbal de Souza Del'OImo (Professor Convidado - UNICURITIBA)}

Na seara política, o Brasil convive com um problema muito sério que é o grande número de cargos de confiança, ou os postos da administração governo que podem ser ocupados sem concurso público e é uma das raízes da corrupção.

Nicolau Maquiavel disse que:

[...] aquele que se entrega, acredita em palavras de astutos, confia e delega em demasia, ficam pobre cedo". É necessário delegar, mas é igualmente necessário controlar rigorosamente as decisões e as ações de quem está à frente do negócio. Tirar o que não lhe pertence faz parte da natureza do homem, somos todos assim, disse Maquiavel (Antonik, 2016, p. 88).

Segundo estudos do jornalista André Petry, esses tipos de cargos são gigantescos, apenas na esfera federal alcançam vinte e três mil.

A nomeação política aniquila a boa gestão, eliminando a possibilidade de uma boa gestão e consequentemente desenvolver seu papel social.

Praticar corrupção custa caro e algumas empresas no Brasil já sofrem as consequências de má gestão e busca por lucro fácil. Nos últimos anos, a população brasileira viu-se diante de inúmeras denúncias de práticas de corrupção, além de inúmeras delações premiadas e acordos de leniência que levaram políticos e empresários para a prisão, além de pagarem altos valores em multa. Portanto, tais práticas, embora ainda existam no Brasil, estão sendo cada vez mais investigadas e certamente levando muitas empresas ao declínio financeiro.

Isso posto, mostra que realmente as práticas de Responsabilidade Social Empresarial, revestidas de eticidade, devem ser a tônica de empresas que buscam a solidificação no mercado. Embora a observância de toda a legislação, com o peso dos tributos, seja realmente um problema para o empreendedor, tendo em vista a concorrência cada vez mais acirrada, o consumidor cada vez mais atento às práticas empregadas socio ambientais aplicas aos negócios, ainda é preferível para se manter no páreo e evitar problemas com o judiciário.

Destacamos que o acordo de leniência foi introduzido na legislação brasileira, efetivamente em 2000, por meio da Lei n. 10.149/2000 que alterou a Lei do CADE (Lei n.8.884/94) 


\section{Personalidade Acadêmica Homenageada:}

Florisbal de Souza Del'Olmo (Professor Convidado - UNICURITIBA)

Já a delação premiada é um recurso que representa o dilema entre cooperar e trair. Tal instituto só existe em países onde os juízes têm grande liberdade de ação, como é o caso do Brasil

A democracia é um sistema de governo onde os cidadãos elegem seus representantes. Um sistema que propicia liberdade ao cidadão, com toda a tutela que a Constituição Federal oferece, no entanto, infelizmente, esse mesmo sistema dá margem para práticas ilícitas por parte de quem deveria proteger os cidadãos de qualquer perigo relacionado a sua liberdade e dignidade.

O Código Penal tipifica a corrupção passiva no seu art.317 com cominação de pena de reclusão de 2 a 12 anos, e multa. Veja que o Código Penal é de 1940, concluindo assim que não faltam leis para punir corrupção, falta seriedade no judiciário e vontade de punir os responsáveis por lapidar o erário.

Jurisprudência: Para configuração do delito de corrupção passiva é necessário que 0 ato de ofício em torno do qual é praticada conduta incriminada seja da competência ou atribuição inerente à função exercida pelo funcionário público (Precedentes do STJ e do STF) (STJ. REsp. 825340/MG, Rel.Min. Felix Ficher, 5a T., DJ 25/9/2006, p.305) (Greco, 2017, p.1108).

Segundo Rogério Greco a respeito de corrupção: "Há um ditado popular que diz que "onde há um corrupto, é porque há também um corruptor" (Greco, 2017, p.1107)

A maioria da população brasileira toma conhecimento dos casos de corrupção pela imprensa, no entanto existem empresas especializadas, no Brasil, que estudam o tema e fazem relatórios que podem auxiliar no combate a esse ato tão corrosivo.

A empresa de consultoria PATRI, fundada no Brasil em 1986, realiza consultoria especializada em políticas públicas e de acordo com sua análise, nos últimos anos, os processos de corrupção chamaram a atenção da sociedade por conta de quatro fatores:

A extensão dos negócios e o volume de dinheiro envolvido nos processos de corrupção; 


\section{Personalidade Acadêmica Homenageada:}

Florisbal de Souza Del'Olmo (Professor Convidado - UNICURITIBA)

\section{A constância do assunto na mídia;}

O debate ostensivo sobre o desafio de se criar regras e controles que mitiguem esquemas de corrupção;

Os casos atuais de corrupção estão levando empresários, executivos e políticos para a prisão; geram aplicações milionárias de multas; e impõem veto à contratação de empresas envolvidas em escândalos de corrupção.

O que traz mudanças no paradigma social com relação à prática de corrupção é o amadurecimento das instituições fazendo com que a sociedade possa acreditar na punição dos corruptos e na prevenção de práticas corrosivas no mercado financeiro.

O Instituto Compliance Brasil, fundado no Brasil em 2014, é uma instituição sem fins lucrativos que se "pauta pela excelência, transparência e independência, orientada ao desenvolvimento do compliance na sua concepção mais ampla". O instituto nasceu do compromisso de profissionais do setor privado brasileiro com o "objetivo primário de propiciar a difusão de informações adequadas, didáticas e de fácil acesso a todos os setores da sociedade.com fluidez e capilaridade, atendendo ao princípio de multidisciplinaridade inerente à matéria"

A Lei n. 12.846/2013 conhecida como Lei Anticorrupção, representa importante avanço ao prever a responsabilidade objetiva, no âmbito civil e administrativo, de empresas que praticam atos lesivos contra a administração pública nacional ou estrangeira.

Jurisprudência

Importante ressaltar que a Lei Anticorrupção foi sancionada em 2013 após uma multidão de pessoas irem às ruas, por todo o território brasileiro, clamar por justiça diante de tantos atos de corrupção que vinha sendo divulgado e pela melhoria dos serviços públicos para atender às necessidades da população.

A legislação brasileira entende por responsabilidade objetiva aquela em que a pessoa que praticou o ilícito responde independentemente de aferição de culpa. Ou seja, se praticou o dano ao erário ou ao ente particular, mesmo que recorra em juízo, responde pelo ato praticado. 


\title{
Personalidade Acadêmica Homenageada: \\ Florisbal de Souza Del'OImo (Professor Convidado - UNICURITIBA)
}

Além de atender a compromissos internacionais assumidos pelo Brasil, a lei fecha uma lacuna no ordenamento jurídico do país ao tratar diretamente da conduta dos corruptos. A Lei Anticorrupção prevê punições como multa administrativa - de até $20 \%$ do faturamento bruto da empresa e prevê também o acordo de leniência de forma mais célere, além da seara investigativa.

Exemplos de boas práticas empresariais, onde as boas práticas elevaram a confiabilidade e os ativos das empresas.

\begin{abstract}
A marca Nestlé, por exemplo, tem grande influência sobre os consumidores, pois a marca carrega a reputação da "responsabilidade suíça". A empresa é respeitada por seus consumidores porque o que faz, ela faz bem, embora não saibamos se seus processos de fabricação tenham certificação ISO. A Nestlé não precisa ficar se jactando que possui certificados, pois anos de postura ética e responsável lhe conferem muita respeitabilidade" (Antonik, 2016, p.77).
\end{abstract}

\section{CONCLUSÃO}

As empresas possuem grande responsabilidade no âmbito social, devendo conhecer e respeitar as legislações pertinentes, além de conhecer a comunidade em que pretende se instalar.

Tanto as leis positivadas quanto as condutas éticas e morais devem ser claras e postas ao conhecimento dos colaboradores para que tenha resultados satisfatórios. É imprescindível o respeito ao meio ambiente que está inserido o empreendimento, sob pena de responder administrativa, civil e penalmente por qualquer infração aos tipos previstos leis vigentes.

As diretrizes sobre Responsabilidade Social Empresarial estão contidas no ISO 26000 , com princípios que regem as condutas dentro das empresas, que devem ser obedecidas com eficiência no gerenciamento, até como forma de coibir práticas ilícitas como a corrupção que além de causar danos irreversíveis para a população, causa grandes prejuízos às empresas e seus dirigentes. 


\section{Personalidade Acadêmica Homenageada:}

\section{Florisbal de Souza Del'Olmo (Professor Convidado - UNICURITIBA)}

Existem no Brasil instituições privadas, como por exemplo o Instituto Compliance Brasil e a empresa de consultoria Patri que estuda e cria mecanismos para informar a sociedade e evitar práticas de corrupção.

Também a Lei n. 12.846/2013 conhecida como a Lei Anticorrupção, crida para atender um anseio da sociedade, que tem por finalidade reconhecer como objetiva a responsabilidade de empresas que praticam atos lesivos contra a administração pública.

Conforme exposto neste estudo, a evolução da sociedade e do direito empresarial caminharam juntos, atendendo as demandas sociais, buscando atender as diretrizes constitucionais e legislações contemporâneas que exigem maior atenção aos direitos sociais, fazendo com que a empresa trabalhe de forma concomitante com o atendimento às demandas sociais, fazendo com que os lucros das empresas não sejam um fim em si mesmos. 
Personalidade Acadêmica Homenageada:

Florisbal de Souza Del'Olmo (Professor Convidado - UNICURITIBA)

\section{REFERÊNCIAS}

ANTONIK, Luis Roberto. Compliance, Ética, responsabilidade Social e Empresarial. $1^{\underline{a}}$ ed. Rio de Janeiro: Alta Books, 2016.

BARBIERI, José Carlo. CAJAZEIRA, Jorge Emanuel Reis. Responsabilidade social Empresarial e Empresa Sustentável, 3aㅡ ed., São Paulo: Saraiva, 2016.

NEGRÃO. Manual de Direito Comercial \& de Empresa, 11 $\underline{\text { a }}$ ed. São Paulo, Saraiva, 2014.

TEIXEIRA, Direito Empresarial Sistematizado, $7^{\text {a }}$ ed. São Paulo, 2018.

FURLAN, Anderson; FRACALOSSI, Willian. Direito Ambiental, $1 \underline{\underline{a}}$ ed. Rio de Janeiro, 2010.

VADE MECUM. Método, Legislação, 8ª ed. Editora Método, São Paulo, 2018. 